\title{
Floral Longevity and Attraction of Arctic Lupine, Lupinus arcticus: Implications for Pollination Efficiency
}

\author{
Clara Reid* \\ University of Victoria \\ nuligag@gmail.com
}

\begin{abstract}
Pollination by insects is a mutualistic relationship in which flowers receive pollen for reproduction while pollinators are rewarded with pollen or nectar. Floral longevity (the period an individual flower blooms) and floral attraction (the period during which pollinators are attracted to the flower, often indicated by petal colour) both play prominent roles in plant and pollinator success. This study investigated whether floral longevity and floral attraction were mediated by pollination type in arctic lupine (Lupinus arcticus S. Wats.), a common herbaceous perennial in northwestern North America. Flowers were either open to pollinators, cross-pollinated by hand, or bagged to prevent cross-pollination, and floral longevity, seed set, and flower colour were observed. Open- and hand-pollinated flowers had significantly shorter floral longevities and higher percent fruit sets than bagged flowers. A colour change of the banner petal marking from white to pink occurred in some flowers and was a signal of floral attraction, as pollinators preferentially visited pre-change flowers. Pre-change flowers contained more pollen and were less likely to have been injured by herbivory than post-change flowers, yet the colour change was not related to pollination type or fruit set. Pollination-induced shortening of floral longevity is likely an adaptation to limited plant resources and pollinator visitation rates. For L. arcticus, this could be influenced by short growing seasons and low annual temperatures in the study area. In the face of climatic changes and shifting species phenologies, the mediation of floral longevity by pollinators could decrease temporal mismatch between plants and their pollinators, yet the many factors at play make this difficult to accurately predict.
\end{abstract}

Keywords: pollination; floral longevity; floral attraction; Lupinus arcticus

\section{Introduction}

$\mathrm{P}$ ollination ecology makes critical contributions to our ecological understanding. Ecosystems are being threatened by climate change, among other factors, which is having rapid and difficult-to-predict effects on plants and pollinators. This is relevant to both agricultural and more natural landscapes in which flowering plants play major structural and functional roles, such as food sources and nutrient cycling. For many angiosperm (flowering plant) species, biotic pollinators (e.g., insects) are required for pollination, a process necessary for plants to reproduce. Therefore,

*I would like to thank my directed studies supervisor Dr. Brian Starzomski for guidance throughout this study and help with editing this manuscript, and for encouraging me to examine the ecosystems I participate in more closely. I am grateful for the Jamie Cassels Undergraduate Research Award, which facilitated this project. 
understanding the complex relationships between plants and their pollinators can help us decipher how ecosystems are being altered as these species are threatened.

Floral longevity and attraction play vital roles in the success of pollination, influencing the quantity and quality of pollen a flower receives as well as the rewards it disseminates to pollinators. These elements therefore affect plant reproductive output and pollinator health (Abdala-Roberts, Parra-Tabla, \& Navarro, 2007). Pollination is necessary for plants to produce (i.e., set) seed, meaning that seed set can be a measurement of pollination success. Floral longevity is defined as the time between opening and senescence of a flower, the senescence being marked by closure, wilting or abscission of petals and sepals. This period varies between several hours to months, depending on the species (Fründ, Dormann, \& Tscharntke, 2011; Stead, 1992; van Doorn, 1997). Although floral longevity is closely related to the time in which a flower can be pollinated, further distinction between floral longevity and floral attraction is useful.

Floral attraction is the period during which a flower is attractive to pollinators (van Doorn, 1997). In some plant species, flowers attract pollinators for their entire floral longevity. In contrast, a colour change of perianth parts, conclusion of scent or nectar production, or a change in orientation can mark the end of floral attraction prior to senescence (van Doorn, 1997). Colour changes in response to pollination have been recorded in over 50 angiosperm (flowering plant) families (Stead \& Reid, 1990; Weiss \& Lamont, 1997), including numerous lupine (Lupinus) species (see, for example, Schaal \& Leverich, 1980; Wainwright, 1978).

Pollination has been shown to decrease floral longevity in multiple species, including many orchids (Orchidaceae), several Lupinus spp., foxgloves (Digitalis), petunias (Petunia), and carnations (Dianthus caryophyllus) (Halevy, 1986), and is more common in angiosperms with floral longevities of more than one day (Stead, 1992). Similarly, pollination can mediate floral attraction (Stead, 1992).

Pollination-induced shortening of floral longevity and attraction is thought to be an adaptation to maximize efficiency of plant-pollinator interactions in the face of resource limitations (Schoen \& Ashman, 1994; Stead, 1992; van Doorn, 1997). For pollinators, the immediate benefit of pollination is a reward, usually in the form of pollen or nectar (Schaal \& Leverich, 1980). Senesced flowers do not provide appreciable rewards and are unlikely to be fertile, so by concluding floral longevity and attraction soon after pollination, plants encourage visitation of well-provisioned fertile flowers (Schaal \& Leverich, 1980). This decreases energy spent by foraging pollinators (Nuttman \& Willmer, 2003).

For plants, shortening of floral longevity in response to pollination can minimize floral maintenance costs. Blooming flowers expend considerable energy through nectar production, water loss via transpiration, and respiration of flower parts (Schoen \& Ashman, 1994). A flower's main function is to be pollinated, which leads to fertilization and seed set, so it is energetically advantageous for a flower to senesce soon after receiving and disseminating adequate pollen (Proctor \& Harder, 1995). Pollinationinduced shortening of floral longevity and attraction also ensures excess pollen is not deposited on stigmas that have already been pollinated, which would cause pollen wastage and heightened competition between growing pollen tubes (Stead, 1992; van Doorn, 1997). These arguments suggest that species which are pollen-limited (due to lack of mates, high plant-pollinator specificity, or pollinator scarcity) or energetically limited (due to high transpiration rates or inadequate nutrients) would exhibit pollinator-induced shortening of floral longevity and attraction more strongly (AbdalaRoberts et al., 2007). This theory is supported by various species, including the white-fringed orchid (Platanthera blephariglottis) and dancing-lady orchid (Cohniella ascendens), which live in hot climates (thus experiencing high levels of transpiration) and have relatively low pollinator visitation rates (Abdala-Roberts et al., 2007; Schoen \& Ashman, 1994).

The mediation of floral longevity and attraction by pollination in some taxa highlights limitations 
in plant-pollinator systems - limitations that could be worsened by climate change. Numerous abiotic factors are being altered in response to changing climatic conditions, which in turn impact the health and phenology of both plants and pollinators (Pieper, Loewen, Gill \& Johnstone, 2011; Straka \& Starzomski, 2015). One issue of interest is timing mismatch between blooming of flowers and activity of their pollinators (Rafferty \& Ives, 2010; Straka \& Starzomski, 2014), which could strain plant-pollinator interactions already suffering from declining pollinator populations (Forrest, 2015). This could negatively affect pollination at the landscape scale. As floral longevity can be mediated by pollination, it is an important factor in plant-pollinator phenological mismatch.

In this study, I examined arctic lupine (Lupinus arcticus S. Wats.) plants for an effect of pollination on floral longevity and floral attraction, the latter being indicated by a colour change. Plants were subject to three pollination manipulations: bagged to prevent insect pollination, bagged and cross-pollinated by hand, and open-pollinated. I observed floral development and potential pollinators, and recorded seed set to measure pollination success.

This research aims to further explicate the complex plant-pollinator interactions of an important boreal species. Although the influence of pollination on floral longevity and attraction has been studied for various Lupinus spp., the published literature has not focused on L. arcticus. Due to its wide distribution and ecological significance, however, studying $L$. arcticus provides useful ecological information. Lupinus arcticus is an herbaceous perennial endemic to northwestern North America, found from Alaska to Oregon (Pieper et al., 2011). It is mainly pollinated by bees, including bumblebees (Bombus spp.) (Straka \& Starzomski, 2015). This plant is also a food source for small mammals, such as arctic ground squirrels (Spermophilus parryii) and snowshoe hares (Lepus americanus) (Willow, Tamayo, \& Jóhannsson, 2017), and improves nutrient availability in soils by fixing nitrogen (Sharam \& Turkington, 2005). In this context, pollen and energetic limitation for $L$. arcticus could have negative demographic consequences for numerous species, especially in the face of our rapidly changing climate. Its widespread distribution makes L. arcticus a potential climate indicator species, reflecting how ecosystems of different latitudes are being affected by climatic changes. Given these factors, studying the pollination ecology of L. arcticus benefits our understanding of numerous species and ecosystems across its range.

\section{Methods}

\section{Study Design}

\section{Study site.}

This study took place at seven sites within a $4 \mathrm{~km} 2$ section of boreal forest in Whitehorse, Yukon, Canada $\left(60.61^{\circ} \mathrm{N}, 134.99^{\circ} \mathrm{W}\right.$, elevation $\left.750 \mathrm{~m}\right)$ during June and July of 2018 . This forest is comprised of a patchy distribution of white spruce (Picea glauca), lodgepole pine (Pinus contorta), and trembling aspen (Populus tremuloides), and major understory plants include soapberry (Shepherdia canadensis), kinnikinnick (Arctostaphylos uva-ursi), twinflower (Linnaea borealis), and feathermosses. Lupinus arcticus was common at all sites. I chose the seven sites to represent the area's varied vegetation compositions and microclimates to help capture the typical behaviour of $L$. arcticus in the study area. The locations of sites are shown in Figure 1.

\section{Pollination manipulations.}

I chose 34 individual $L$. arcticus plants, about five per study site. I used a paired design, with each plant as one replicate $(\mathrm{N}=34)$ and each plant being exposed to all three pollination treatments. On each plant, I chose three inflorescences (stems of flowers) at similar developmental stages and 

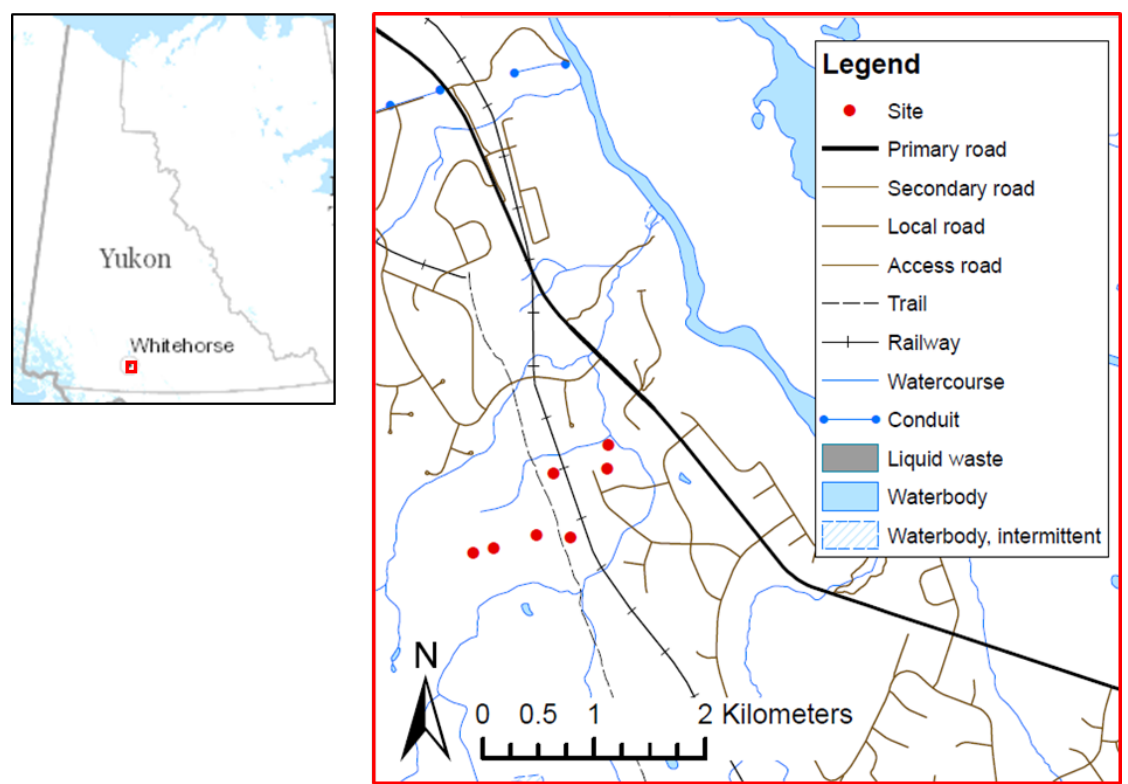

Figure 1: Study sites were in Whitehorse, Yukon (above). Southern Whitehorse is expanded on the right to show the locations of the seven study sites. Maps were created using ArcMap 10.6.1 (ESRI, USA, 2018) with data from Geomatics Yukon (Geomatics Yukon, Yukon, 2019).

subjected each to one of the three pollination treatments: bagged, cross-pollinated by hand, and open-pollinated. For the bagged and hand-pollination treatments, I enclosed the inflorescence in a pollinator-exclusion bag prior to blooming. These bags were made of $1 \mathrm{~mm}$ mesh, measured approximately $10 \times 20 \mathrm{~cm}$, and were fastened around the inflorescence's stem with a drawstring to prevent insects (larger than $1 \mathrm{~mm}$ in diameter) from accessing the flowers. I did not further manipulate inflorescences in the bagged pollination treatment. For the hand-pollination treatment, I cross-pollinated each flower at least once while in bloom, using pollen from blooming conspecifics 10-30 m from the treated plant. This pollen source was chosen because $10-30 \mathrm{~m}$ is a distance likely traveled by pollinators, but is far enough to decrease the chance of applied pollen being genetically similar to the treated plant (since Lupinus are known to eject their seeds up to six metres (Dunn, 1956)). Hand-pollination was done by depressing the wing and keel petals to expose the stigma (Figure 2), to which pollen was applied; the same action is done by bees pollinating Lupinus (Wainwright, 1978). Open-pollinated inflorescences remained exposed to natural pollinators and were not hand-pollinated.

These three pollination manipulations address the potential reproductive systems of L. arcticus. Lupinus arcticus is insect pollinated (Straka \& Starzomski, 2015), in which pollen deposited on a flower's stigma often originates from a different plant (i.e., cross-pollination). The open-pollination treatment captured this activity, while the hand-pollination treatment provided a base level of guaranteed cross-pollination to compare insect pollination to. Since the bagged pollination treatment excluded insect pollinators, any seeds produced would likely be the result of self-pollination. Thus, seeds produced in this treatment would suggest that L. arcticus is self-fertile, which has not been confirmed. Given the complexity of plant reproductive systems, this study does not seek to determine whether $L$. arcticus is self-fertile (one consideration is bagged undisturbed vs. bagged self-pollinated flowers, as described, for example, in Barrett \& Helenurm, 1986). 


\section{Floral development and seed set.}

I recorded floral development every two days during peak blooming and approximately every five days while pods matured. At each observation event, I classified the flowers of all treatments into seven stages. These stages are as follows: 1) closed - flower bud is tightly folded against the inflorescence rachis; 2) almost blooming - flower has extended away from the rachis and banner remains folded over wings and keel; 3) starting to bloom - banner petal has partially unfolded; 4) blooming white - banner is fully erect and the centre of the banner is white; 5) blooming pink - banner is fully erect and the centre of the banner is light to dark pink; 6) starting to wilt-one or more petals wilting; and 7) wilted - all petals dried and shrivelled. I further examined flowers in stage seven for pod formation, which was indicated by a swelling ovary. Anatomy of L. arcticus is shown in Figure 2. To help keep track of individual flowers, inflorescences were divided into vertical tiers, each with approximately five or six flowers. I counted the number of pods per inflorescence and the number of fully developed seeds per pod when pods approached maturity, but before they had split and released their seeds.
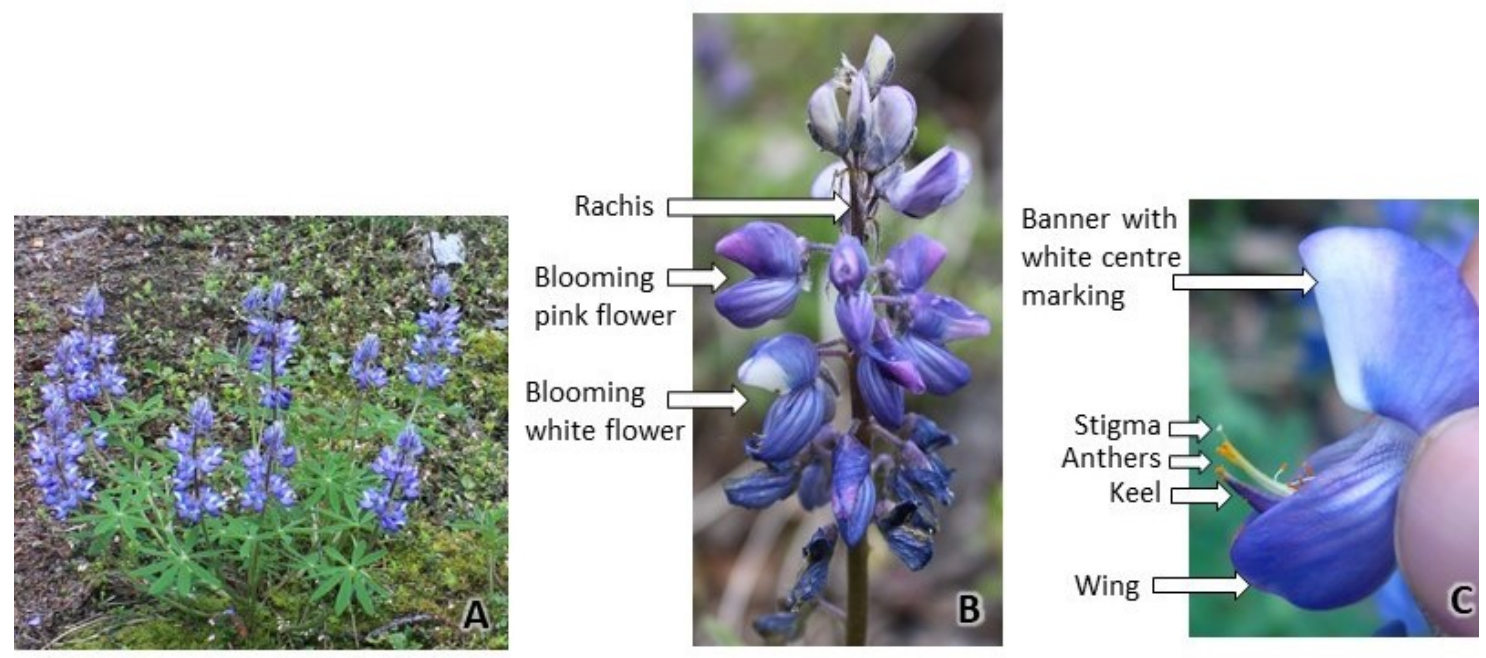

Figure 2: Anatomy of a Lupinus arcticus plant. A: One plant with multiple inflorescences. B: One inflorescence showing the central stem (rachis) and flowers at various stages of development. C: Anatomy of a single flower in bloom showing the keel, wing, and banner petals. The stigma (component of pistil where pollen is deposited) and anthers (component of the stamens containing pollen) are originally located inside the keel petal. Depressing the keel and wing petals forces the stigma, anthers, and pollen to emerge from the tip of the keel. This action is done during pollination.

\section{Further plant characteristics.}

To determine whether pollinator-exclusion bags affected plant growth, I measured the height of each treated inflorescence on all days that floral development observations were made, until they reached their maximum height.

I counted the number of pods per inflorescence for inflorescences that were not treated, but were on treated plants. By comparing this to open-pollinated inflorescences, an effect of handling plants (while examining floral development) on reproductive output could be determined. 
The Arbutus Review • $2019 \bullet$ Vol. 10, No. 1 • https://doi.org/10.18357/tar101201918921

\section{Potential pollinator counts.}

To assess whether flowers in the open-pollination treatment were being pollinated, I observed bumblebees and honeybees (Apidae: Bombus spp. and Apis spp., respectively), other bees (e.g., Andrenidae and Megachilidae), and hoverflies (Syrphidae) while examining floral development. Taxa were recorded if they were seen (or heard, in the case of Bombus spp.) within approximately $10 \mathrm{~m}$ of the plant being observed. Furthermore, the plant species being visited by the insects were noted. Observation periods were roughly 20 minutes per plant while L. arcticus was in full bloom and less time per plant when pods were maturing.

\section{Data Analysis}

I analyzed data using both an independent and a paired design. The independent design helped me to visualize data more easily, while the paired design eliminated the effects of inherent differences between plants on response variables. When the data were treated independently, each inflorescence was treated as one replicate. Each inflorescence had between 7 and 33 flowers $(\bar{x}=18.108, \mathrm{SD}=$ 5.157 ), necessitating the calculation of averages or percentages for each inflorescence to effectively compare replicates. In the paired design, each plant was treated as one replicate. Each plant had three inflorescences that were studied, each subject to one of the three pollination treatments. I used one-way ANOVAs or their non-parametric alternatives to analyze floral longevity, seed set, and further plant characteristics data because they are a clear way of determining and visualizing how categorical pollination manipulations - the explanatory variable of focus - affect a numerical response variable. All data were analyzed using Minitab version 18.1 (Minitab Software, USA, 2017).

\section{Floral longevity.}

I calculated floral longevity as the total number of days a flower was in development stages 4 (blooming white) and 5 (blooming pink). Values were averaged across all flowers within each inflorescence.

When I analyzed the mean floral longevity independently of the paired design, I calculated the mean floral longevity for each pollination treatment from the average floral longevities for all inflorescences subject to that treatment and compared these using a one-way ANOVA and Tukey-Kramer post-hoc test. To preserve the paired design of the study, I analyzed the data by calculating the difference in floral longevity between paired inflorescences (i.e., those on the same plant, but subject to different treatments). This was done for all three treatment pairs: "bagged

- open-pollinated," "bagged - hand-pollinated," and "open-pollinated - hand-pollinated." These data did not show major deviations from the assumptions of normality and equal variances, so floral longevity differences for the treatment pairs were compared using a one-way ANOVA and Tukey-Kramer test.

\section{Reproductive output.}

Percent fruit set was defined as the percent of flowers that formed pods on a given inflorescence. I analyzed data as independent and paired, using the same methods as described for floral longevity data. For the independent analysis, I compared the mean percent fruit sets with a one-way ANOVA and Tukey-Kramer test. For the paired analysis, the data were not normally distributed, necessitating a Kruskal-Wallis test to compare treatment pairs. I then used paired t-tests with significance thresholds of 0.05 to test the null hypothesis that percent fruit set did not differ between pairs of treatment pairs. 
The Arbutus Review • $2019 \bullet$ Vol. 10, No. 1 • https://doi.org/10.18357/tar101201918921

I also calculated the average number of seeds per pod for inflorescences with seed set and compared the mean values for the three pollination treatments using a one-way ANOVA.

\section{Stages of floral development.}

I calculated the percent of flowers in a given stage of development by dividing the number of flowers in the given stage by the total number of flowers attached to the inflorescence at that date. This was done for all seven stages of development (closed, almost blooming, starting to bloom, blooming white, blooming pink, starting to wilt, wilted), with the addition of a "pod forming" category (a subdivision of the "wilted" stage). I plotted these data against time and visually examined the plots for patterns.

\section{Further plant characteristics.}

I calculated the growth rate of all treated inflorescences as the change in height, in $\mathrm{cm} /$ day, for the first 10 or 11 days of observation (during which the maximum height was achieved for most plants). This was used to determine whether growth rate varied significantly between pollination treatments. I calculated differences in growth rate between paired inflorescences in a similar method to floral longevity and percent fruit set analyses and used a one-way ANOVA to compare pollination treatments.

The number of pods per inflorescence was further calculated for inflorescences that were on the studied plants, but not subject to pollination treatments. I calculated this average value for each plant and compared it to that of the plant's open-pollinated inflorescence. I used a paired t-test with a significance threshold of 0.05 to test the null hypothesis that handling plants did not affect their pod production.

\section{Potential pollinator counts.}

Using data from the entire study duration, I determined the number of pollinator observations for the three following taxa: Syrphidae, Bombus, and other bees. I further subdivided these categories into observations on $L$. arcticus and on other plant species. Plots of these data were used to qualitatively assess the likelihood that $L$. arcticus in the open-pollination treatment were insect pollinated.

\section{Results}

\section{Floral Longevity}

Pollination treatment had a significant effect on the average floral longevity of each inflorescence. When data were analyzed as independent (rather than paired), floral longevity for bagged inflorescences was significantly longer than for hand- and open-pollinated inflorescences (Tukey-Kramer $\mathrm{T}=$ 4.63, $\mathrm{P}<0.001$ for bagged vs. hand-pollinated; $\mathrm{T}=5.33, \mathrm{P}<0.001$ for bagged vs. open-pollinated inflorescences). Floral longevities of hand and open-pollinated inflorescences were similar $(\mathrm{T}=0.71$, $\mathrm{P}=0.761)$. A plot of the mean floral longevities is shown in Figure 3. The same patterns were revealed when data were analyzed as pairs (in which each data point was the difference in floral longevity between inflorescences that were on the same plant but subject to different pollination treatments). 


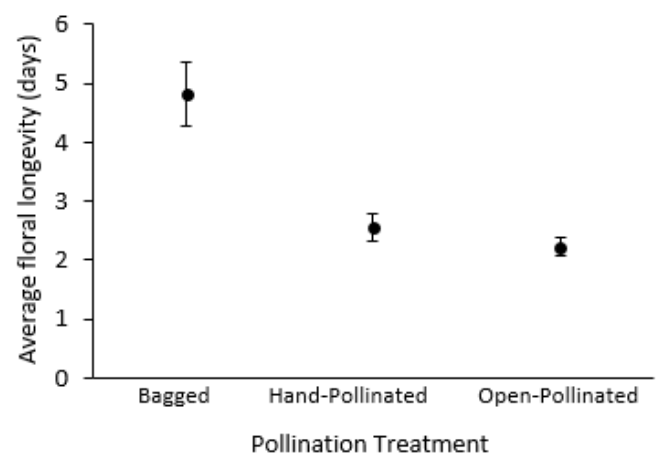

Figure 3: Mean and standard error of floral longevity of flowers on inflorescences subject to three pollination treatments: bagged, hand-pollinated and open-pollination. $N=34$ for all treatments.

\section{Reproductive Output}

Pollination affected percent fruit set, but not the number of seeds per fruit. Calculations of percent fruit set included inflorescences that did not set any fruit ( $\mathrm{N}=33$ for each treatment). When all inflorescences were treated independently, the percent fruit set was significantly lower for the bagged inflorescences than the hand- and open-pollinated inflorescences (Tukey-Kramer $\mathrm{T}=-4.78, \mathrm{P}<0.001$ for bagged vs. hand-pollinated, and $\mathrm{T}=-3.20, \mathrm{P}=0.005$ for bagged vs. open-pollinated inflorescences). Percent fruit set was highest for hand-pollinated inflorescences, which was statistically similar to open-pollinated inflorescences (Tukey-Kramer $\mathrm{T}=1.58, \mathrm{P}=0.259$ ). The mean percent fruit sets for each treatment are shown in Figure 4. When I analyzed data to preserve the paired study design, a non-parametric Kruskal-Wallis test gave a significant P-value of 0.022. Paired t-tests revealed the same patterns as when data were analyzed as independent.

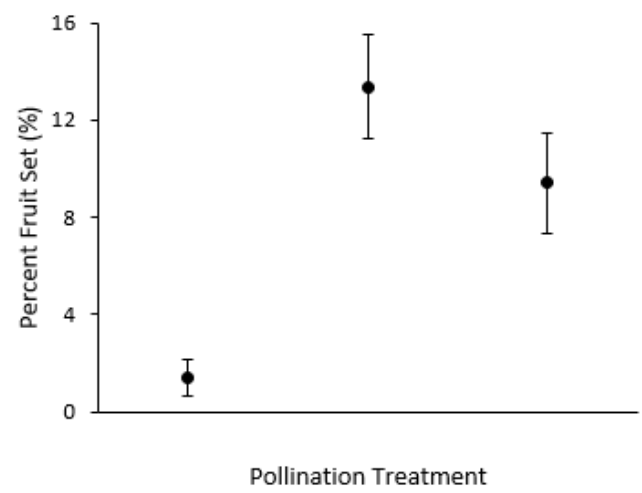

Figure 4: Mean and standard error of percent fruit sets for the three pollination treatments: bagged, hand-pollinated and open-pollinated. $N=33$ for all treatments. 
The average number of seeds per pod was statistically similar between all pollination treatments (one-way ANOVA $\mathrm{P}=0.675$ ). These data are shown in Figure 5.

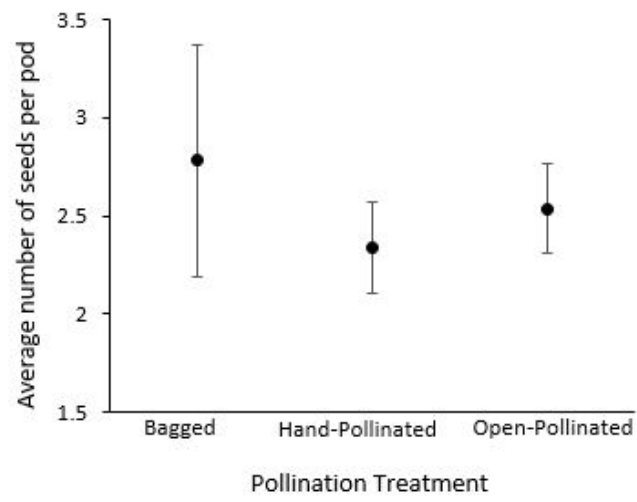

Figure 5: Mean and standard error of the number of seeds per pod for the three pollination treatments. Data does not include flowers that did not set seed. The pollination treatments are as follows: bagged $(N=5)$, hand-pollinated $(N=26)$, open-pollinated $(N=19)$.

\section{Stages of Floral Development}

I observed that the date flowers began to bloom was similar for all pollination treatments. In all flowers, the banner petal had a white marking at its center when it first opened (floral development stage 4 , blooming white), and in some flowers, this banner section turned pink (stage 5 , blooming pink) before the flower wilted or fell off. Blooming white and blooming pink flowers are shown in Figure 2. Blooming pink flowers accounted for up to one-third of blooming flowers on a given day, as depicted in Figure 6. Flowers with either white or pink banner markings were observed setting fruit. Additionally, many flowers that did not undergo a colour change wilted without forming fruit. I observed these patterns in all pollination treatments.

\section{Further Plant Characteristics}

I analyzed plant characteristics to determine if handling inflorescences affected their growth rate and pod production. Growth rate was not significantly different between inflorescences of the same plant that were subject to different pollination treatments (one-way ANOVA $\mathrm{F}=0.31, \mathrm{P}=0.732$ ). The average number of pods per inflorescence was not significantly different between untreated and open-pollinated inflorescences on the same plant (paired t-test $\mathrm{T}=0.13, \mathrm{P}=0.896$ ).

\section{Potential Pollinator Counts}

I noted a total of 36 Syrphidae, 48 Bombus spp., and five other bee taxa during the study (June 14 to July 23) with observations at all study sites (Figure 7). I observed four Bombus spp. and two other bee individuals pollinating $L$. arcticus, and 23 Syrphidae at L. arcticus, although pollination was not observed for this family. Potential pollinators appeared to be most active near noon each day and at temperatures between $15^{\circ} \mathrm{C}$ and $24^{\circ} \mathrm{C}$. 

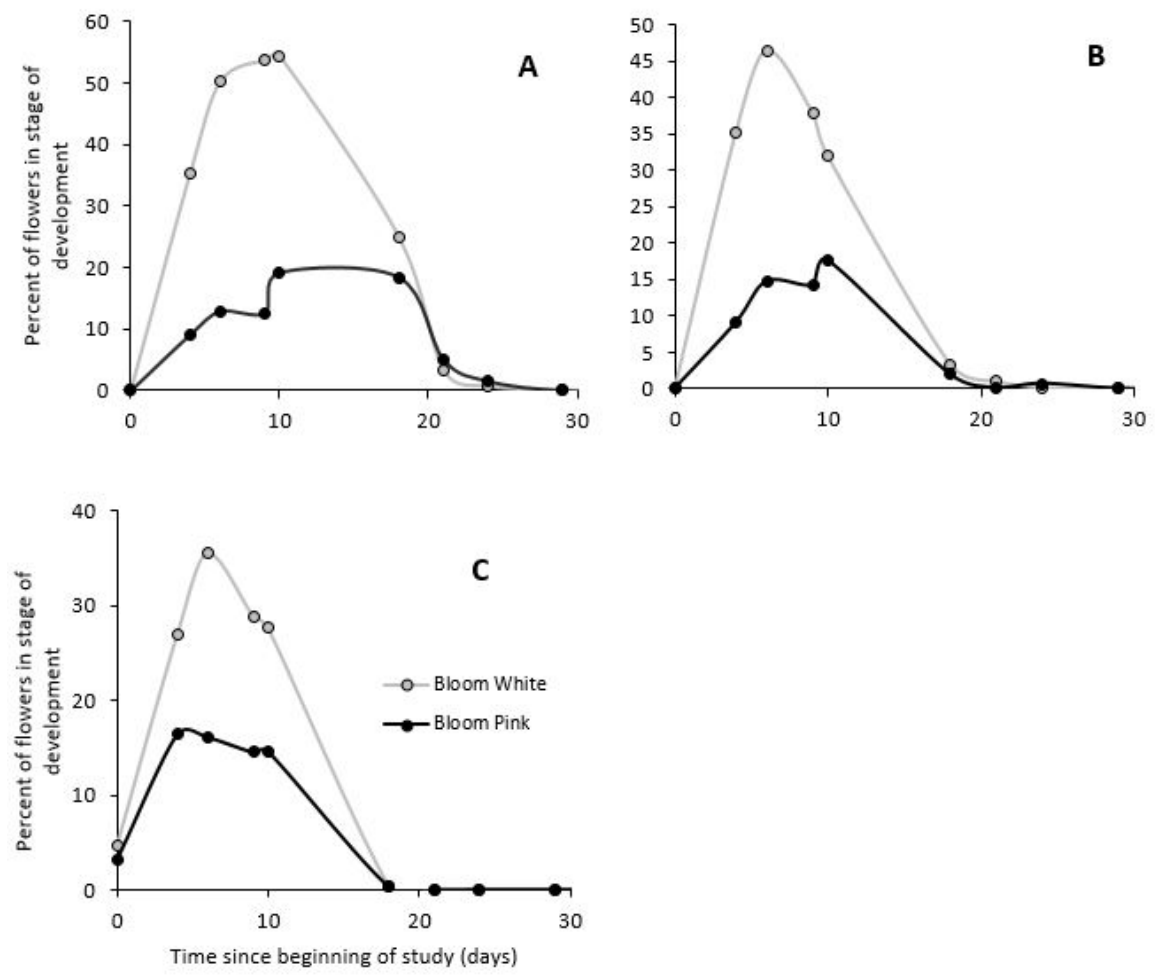

Figure 6: The percent of flowers that are blooming with a white banner marking ("Bloom White," grey) and a pink banner marking ("Bloom Pink," black) over the first 30 days of the study. Each plot is for a different pollination treatment. A: bagged, B: hand-pollinated, C: open-pollinated.

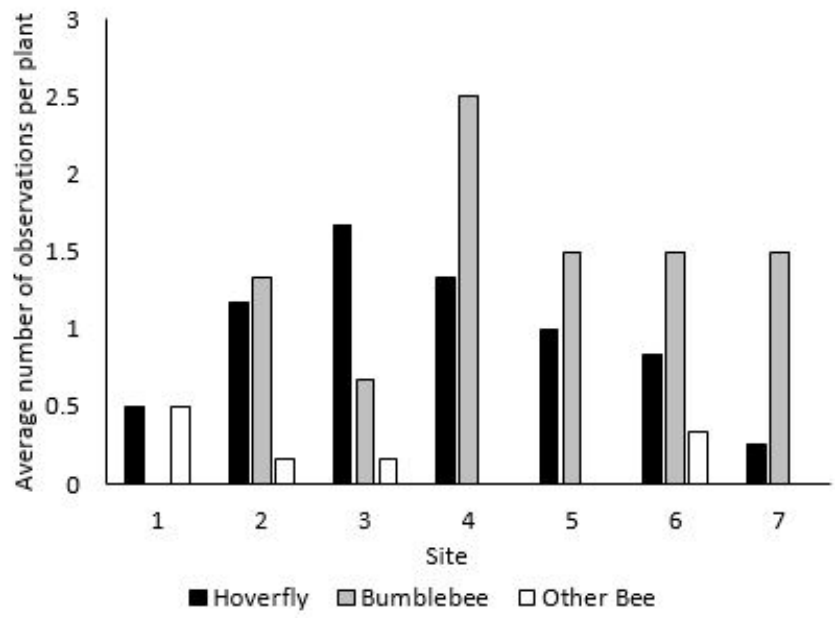

Figure 7: Figure 7. The average number of hoverflies (Syrphidae), bumblebees (Bombus spp.), and other bees (e.g., Andrenidae) observed per plant during the study, at each site. Observations occurred during $\leq 20$ minutes every two days. 


\section{Discussion}

In this study, I found that floral longevity of Lupinus arcticus was mediated by pollination, as bagged flowers had significantly lower percent fruit set (indicating unsuccessful pollination) and significantly longer floral longevities than hand- and open-pollinated flowers. The period of floral attraction, concluded by a colour change of the banner petal from white to pink, was not influenced by pollination, but likely affects pollinator activity. These results have implications for the efficiency of plant-pollinator interactions and phenological mismatch. With the threats currently facing ecosystems, such as diseases and extreme weather events, the future abundance, distribution, and behaviour of species is uncertain. By revealing pollination processes in the widespread L. arcticus, this study can help predict ecological responses to environmental changes.

\section{Effects of Pollination on Floral Longevity}

By comparing floral longevity between pollination treatments, I showed that floral longevity was significantly longer for bagged flowers than those that were cross-pollinated by hand or openpollinated (Figure 3). I recorded potential pollinators including Bombus spp. and other bees at all sites and observed several of these insects directly pollinating L. arcticus flowers (Figure 7). This confirms that flowers in the open-pollination treatment were insect-pollinated. These observations show that outcrossing both by hand and natural pollinators induces a shortening of floral longevity when compared to flowers that are only able to self-pollinate.

Percent fruit set is a metric of reproductive output and was used to measure pollination success. Percent fruit set data confirmed that inflorescences with shorter floral longevities had more successful pollination. Conversely, longer floral longevities coincided with less successful pollination. The percent fruit set was significantly lower for bagged inflorescences than those that were hand-pollinated and open-pollinated (Figure 4). The low seed set of bagged L. arcticus inflorescences indicates unsuccessful pollination and has previously been observed by Straka and Starzomski (2015). This may suggest that this species is self-incompatible. It is unlikely that manipulating the inflorescences played a role in these results, since I found inflorescence growth rate to be similar between all treatments. Furthermore, I did not find a significant difference in number of pods per inflorescence between inflorescences in the open-pollination treatment and those that were on the same plant but not subject to experimental manipulation.

Shortening of floral longevity in response to pollination with genetically compatible pollen has previously been described in numerous taxa, including tropical and temperate orchids such as the fairy slipper orchid (Calypso bulbosa) (Proctor \& Harder, 1995), Digitalis, Dianthus caryophyllus (Stead, 1992), Petunia (Halevy, 1986), and, of taxonomic relevance to this study, Lupinus nanus (Dunn, 1956). The presence of this pattern in L. arcticus confirms the widespread geographical and taxonomic range of this phenomenon.

\section{Resource and Pollinator Limitation}

Pollination-induced shortening of floral longevity is thought to be an adaptation to increase efficiency of plant-pollinator interactions, therefore potentially improving the fitness of plants and pollinators. This occurs because the senescence of pollinated flowers directs pollinators towards flowers that are more likely to have rewards (e.g., nutritious pollen) and be reproductively viable (Schaal \& Leverich, 1980; van Doorn, 1997). Furthermore, senescence of pollinated flowers decreases the energy a plant spends on floral maintenance. These ideas imply that flowers exhibiting pollinationinduced floral senescence are likely limited by abiotic resources, pollen, and/or pollinator visitation (Schoen \& Ashman, 1994). This notion is supported by multiple tropical orchid species, including 
Cohniella ascendens (Abdala et al., 2007), Dendrobium spp. (Luangsuwalai, Paull, \& Ketsa, 2013), and Platanthera blephariglottis, which frequently have high plant-pollinator specificity (corresponding with low pollination visitation rates) and high floral maintenance costs (due in part to high transpiration rates in hot climates) (Schoen \& Ashman, 1994).

This study may provide evidence of limited pollination or plant growth resources in a widespread and ecologically important species. From some perspectives, this seems surprising. Lupinus arcticus is common throughout most of its range, including the boreal forest in which this study took place (Pieper et al., 2011; Sharam \& Turkington, 2005), so a shortage of mates seems unlikely. Further, Lupinus spp. are mostly pollinated by Bombus spp. (Schaal \& Leverich, 1980; Wainwright, 1978), and high-latitude Bombus spp. can be active at lower temperatures than many other pollinators (personal observation). These factors decrease the chances of pollen limitation. Additionally, $L$. arcticus fixes nitrogen (Sharam \& Turkington, 2005), so is less likely to have nutrient shortage than coexisting plant species.

Despite these factors, L. arcticus may face pollination and plant growth limitations. The percent fruit set observed in this study was slightly lower for open-pollinated than hand-pollinated inflorescences (Figure 4). This is evidence for pollen-limitation in L. arcticus and is likely the result of limited pollinator activity (rather than mate availability). Support for this hypothesis comes from a study of several alpine plant species in the Coast Mountains of British Columbia, which showed that abundance of potential pollinators was weakly correlated with seed set in L. arcticus (Straka \& Starzomski, 2015). The short growing season and permafrost present throughout much of this plant's range may also decrease availability of temperatures, soil moistures, and nutrient concentrations optimal for this species' growth (Pieper et al., 2011). Although a study between 1999 and 2008 in the alpine near Whitehorse, Yukon revealed that vegetative growth of L. arcticus was resilient to temperature fluctuations, number of inflorescences per plant was significantly correlated with number of days per season above $5^{\circ} \mathrm{C}$ (Pieper et al., 2011). Similarly, Straka and Starzomski (2015) found that temperature was a weak predictor of $L$. arcticus seed set in a Coast Mountains population. It would be interesting to see if pollination-limitation and a relationship between pollination and floral longevity exists in other populations across this species' range. If so, these limitations could be altering ecosystems by changing the extent and behaviour of L. arcticus and therefore its competitors, influencing species such as herbivores that depend upon them.

\section{Plant Physiology Behind Floral Senescence}

The method by which pollination causes floral senescence has been closely studied in numerous species (Halevy, 1986; Luangsuwalai et al., 2013; Stead, 1992; Stead \& Reid, 1990; van Doorn, 1997). Ethylene, produced at the highest rate in the pistil shortly after pollination, is largely thought to cause the wilting and colour changes observed in perianth parts in species including Lupinus albifrons (Stead \& Reid, 1990). The method by which pollination signals ethylene production has not been confirmed, but may include damage to nectaries by pollinating insects (Stead, 1992), pollen germination, or growth of pollen tubes in the style (Nuttman \& Willmer, 2003). Since hand-pollinated flowers in this study showed similar floral longevities to open-pollinated flowers, it is assumed that hand-pollination induced these processes in the same way as natural pollination.

\section{Colour Change and Floral Attraction}

In this study, I observed that almost all L. arcticus flowers had a white mark in the centre of the banner petal upon opening, and that this turned pink in some flowers (Figure 2). I did not find a relationship between colour change and pollination treatment or fruit set. This suggests that 
in L. arcticus, colour change is independent of pollination and does not always occur with floral maturation. This could be expected, given the diversity of Lupinus species.

For Lupinus flowers, the banner marking often changes colour, but predictors of this vary. Much like pollination-induced shortening of floral longevity, pollination (and ethylene production) has been correlated with colour changes in Lupinus albifrons (Stead \& Reid, 1990), L. pilosus (Ne'eman and Nesher, 1995; Nuttman \& Willmer, 2003), and L. nanus (Dunn, 1956). In several of these species, colour changes occur naturally, but are enhanced by pollination. Colour changes that are not pollination-induced occur in L. arizonicus, L. sparsiflorus (Wainwright, 1978), and L. texensis (Schaal \& Leverich, 1980). Despite the variation between Lupinus spp., this colour change is an important signal of floral attraction to pollinators.

Many insect pollinators forage based on visual cues (Weiss \& Lamont, 1997), and thus colour can indicate floral attraction, with implications for pollinator efficiency (van Doorn, 1997). Bees, which are the main pollinators of Lupinus (bees include Apidae, Andrenidae, and Megachilidae) are attracted to white and yellow flowers (Wainwright, 1978). The white banner petal marking of most Lupinus flowers is an orientation point for bees (Wainwright, 1978), while the rest of the petals are a dark colour (e.g., violet). This white banner marking often darkens during blooming, decreasing the colour contrast present in the flower and thus its attractiveness to bees (van Doorn, 1997). Numerous studies and personal observations have revealed that more than 95

The colour of Lupinus banner markings likely overlaps with floral fertility (pollen viability and stigma receptivity) as well as pollinator rewards. This has been shown for L. pilosus whose flowers with pink markings contained less pollen than those with white markings (Nuttman \& Willmer, 2003), a pattern I observed for L. arcticus in this study. As such, colour changes and pollinator colour preferences maximize pollination of fertile flowers and pollinator foraging efficiency.

It is interesting to note that periods of floral attraction and floral longevity do not always coincide completely. In several taxa, including Lupinus, lilies (Lilium), and the orchids green antelope orchid (Dendrobium antennatum) and eggleaf twayblade (Listera ovata), flowers continue to bloom after a colour change has signified the end of floral attraction (Schoen \& Ashman, 1994; van Doorn, 1997). The energy expended on maintaining non-attractive (and possibly non-viable) flowers is justified when these flowers add to a plant's overall floral display and therefore increase visitation of viable, attractive flowers (Abdala-Roberts et al., 2007; van Doorn, 1997). For example, a Lupinus inflorescence with 30 blooming flowers ( 15 with pink and 15 with white banner markings) is likely to attract more pollinator visits than one with only 15 white-marked flowers and 15 non-attractive wilted flowers. Since pollinators preferentially visit white-marked Lupinus flowers, the former inflorescence will experience more pollinator visits per flower.

In many species, colour change is the result of pollination, but it also can be caused by injury. In this study, when dissecting $L$. arcticus flowers, I found that most $(>75 \%)$ flowers with pink banner markings contained a white maggot that was eating the flower's ovary, preventing it from setting seed. Further, I noticed that flowers with pink markings appeared to abscise more easily than those with white markings. This represents significant damage to the reproductive output of L. arcticus, especially since up to a third of blooming flowers had pink markings (Figure 6). Premature flower abscission due to this herbivory likely contributed to the large variation in floral longevities present in all pollination treatments.

Infestation with maggots probably causes a colour change in L. arcticus due to the plant's response to injury. When injured, plants release ethylene, the same chemical that induces colour change in Lupinus albifrons, L. pilosus, and other taxa (Nuttman \& Willmer, 2003; Stead, 1992). A colour change in response to injury (e.g., squeezing of the style, which is directly attached to the ovary) has also been observed in L. nanus (Dunn, 1956). This is strong evidence that herbivory of the ovaries in L. arcticus flowers incites a colour change. 


\section{Implications for Plant-Pollinator Mismatch}

Plant-pollinator mismatch is a phenomenon in which the blooming of flowers does not coincide temporally with the activity of their pollinators (Forrest, 2015; Straka \& Starzomski, 2014). The extent of complete mismatch is not well understood (Forrest, 2015), but could have severe consequences for plants (reduced seed set) and pollinators (reduced food sources). In this study, pollination of L. arcticus was shown to decrease floral longevity, a process thought to increase the efficiency of plant-pollinator interactions while decreasing floral maintenance costs (Schoen \& Ashman, 1994; van Doorn, 1997). As climate change alters the phenology of both plants and pollinators, this effect may decrease the chance of plant-pollinator mismatch. For instance, if plants exhibiting pollination-induced shortening of floral longevity experience warmer temperatures that stimulate them to bloom several days before the peak of pollinator activity, absence of pollination at the beginning of blooming will result in longer floral longevities, ensuring that flowers continue to bloom when pollinators are most active. This will ensure pollination occurs, and thus the partial phenological mismatch should not have considerable consequences for pollinator and plant success. Decreased floral attraction in response to pollination can function in much the same way, as it directs pollination activities towards viable flowers and thus maximizes pollination per pollinator's energy expenditure (Schoen \& Ashman, 1994; van Doorn, 1997; Weiss \& Lamont, 1997).

Despite the positive impacts these flowering behaviours could have on plant and pollinator health, there may also be negative ramifications. Lengthened floral longevities in the absence of pollination causes more energy to be spent maintaining flowers, leaving less for seed production if pollination does eventually occur. This has been demonstrated by the higher seed set of flowers pollinated soon after opening in comparison to those pollinated later (Ashman \& Schoen, 1997, as cited in Abdala-Roberts et al., 2007). Additionally, maintaining floral structures can increase a plant's risk of herbivory and fungal infection (van Doorn, 1997) and rate of transpiration, especially in the face of increasing temperatures and expanding pathogen and pest distributions. A corresponding issue arises for pollinators. Pollinator rewards (e.g., nectar and pollen) are made available close to the beginning of blooming, and as the flower blooms, the quality of these rewards may decrease. For instance, pollen of one-day-old Lupinus texensis flowers sticks to the pollen sacs and abdomen of bee pollinators more readily than powdery older pollen (Schaal \& Leverich, 1980). Thus, visiting older blooming flowers may be worse for pollinator health. As evidenced, many factors are at play in this complex interaction (Straka \& Starzomski, 2014).

It is important to note that not all pollinators are equally effective (Straka \& Starzomski, 2014). Due to the anatomy of Lupinus flowers, bee pollinators are necessary to activate the piston pollination mechanism. Furthermore, Bombus spp. complete this function more efficiently than smaller bees (personal observation; Wainwright, 1978). During this study, I observed other pollinating insects including Syrphidae frequently visiting L. arcticus, as did Chironimidae, Muscidae, and Bibionidae on subarctic L. nootkatensis in a study by Willow et al. (2017). Despite their abundance, these insects likely do not pollinate Lupinus, but are effectively pollen-stealers (Wainwright, 1978). This highlights the need for accurate understanding of plants' pollinators if plant-pollinator mismatch is to be evaluated. Factors affecting pollinator activity are also important. In this study, highest pollinator activity was observed between 15 and $24^{\circ} \mathrm{C}$. Temperatures above this range did occur but are uncommon for the study area, and as hot spells become more common with climate change, pollinator activity could suffer.

The fact that pollination-induced shortening of floral longevity has evolved in L. arcticus and other species suggests that pollen and resource limitation has occurred for a considerable amount of time. Pollen-limitation is the current reality for most flowering plants (Straka \& Starzomski, 2015). Due to a lack of research, the number of taxa in which the aforementioned pollination-induced 
effects occur is not well known, but may be half of all angiosperms (Stead, 1992; van Doorn, 1997). Depending on behavioural plasticity and rates of evolution, pollination-induced shortening of floral longevity and floral attraction could become a stronger pattern if plant-pollinator mismatch worsens.

\section{Conclusion}

In this study, I observed pollination-induced shortening of floral longevity in Lupinus arcticus, a widespread boreal herb pollinated by bees. Additionally, a floral colour change (likely associated with herbivory of the floral ovary) occurred, decreasing attractiveness of these flowers to pollinators. These effects are thought to increase pollination efficiency by directing pollinators and plant resources towards blooming, viable flowers. This suggests that pollination and resources are limited for this plant species, a condition which could worsen as the climate changes and plant and pollinator phenologies shift. Pollination-mediated floral longevity may decrease the chance of mismatched plant-pollinator phenologies; however, the range of factors affecting this situation makes accurate predictions difficult. Due to the integral ecological roles plants and pollinators play, including food sources, nutrient cyclers, and creators of structural complexity, healthy plant-pollinator relationships are necessary for ecosystems to function optimally. This study has revealed the flexibility of an $L$. arcticus plant-pollinator interaction, exposing both the limitations and adaptability of species. 
The Arbutus Review • $2019 \bullet$ Vol. 10, No. 1 • https://doi.org/10.18357/tar101201918921

\section{References}

Abdala-Roberts, L., Parra-Tabla, V., \& Navarro, J. (2007). Is floral longevity influenced by reproductive costs and pollination success in Cohniella ascendens (Orchidaceae)? Annals of Botany, 100, 1367-1371. https://doi.org/10.1093/aob/mcm219

Barrett, S. C. H., \& Helenurm, K. (1986). The reproductive biology of boreal forest herbs. I. Breeding systems and pollination. Canadian Journal of Botany, 65, 2036-2046. https://doi.org/10.11 $39 / \mathrm{b} 87-278$

Dunn, D. B. (1956). The breeding systems of Lupinus, Group Micranthi. The American Midland Naturalist, 55(2), 443-472. https://doi.org/10.2307/2422606

Forrest, J. R. K. (2015). Plant-pollinator interactions and phenological change: What can we learn about climate impacts from experiments and observations? Oikos, 124, 4-13. https://doi.org/10.1111/oik.01386

Fründ, J., Dormann, C. F., \& Tscharntke, T. (2011). Linné's floral clock is slow without pollinators-flower closure and plant-pollinator interaction webs. Ecology Letters, 14, 896-904. https://doi.org/10.1111/j.1461-0248.2011.01654.x

Halevy, A. H. (1986). Pollination-induced corolla senescence. International Society for Horticultural Science, 181(2), 25-32. https://doi.org/10.17660/ActaHortic.1986.181.2

Luangsuwalai, K., Paull, R. E., \& Ketsa, S. (2013). Compatible and incompatible pollination and the senescence and ovary growth of Dendrobium flowers. European Journal of Environmental Sciences, 3(1), 35-42. https://doi.org/10.14712/23361964.2015.21

Ne'eman, G., \& Nesher, R. (1995). Pollination ecology and the significance of floral color change in Lupinus pilosus L. (Fabaceae). Isreal Journal of Plant Sciences, 43(2), 135-145. https://doi.org/10.1080/07929978.1995.1067659

Nuttman, C., \& Willmer, P. (2003). How does insect visitation trigger floral colour change? Ecological Entomology, 28, 467-474. https://doi.org/10.1046/j.1365-2311.2003.00527.x

Pieper, S. J., Loewen, V., Gill, M., \& Johnstone, J. F. (2011). Plant responses to natural and experimental variations in temperature in alpine tundra, southern Yukon, Canada. Arctic, Antarctic, and Alpine Research, 43(3), 442-456. https://doi.org/10.1657/1938-4246-43.3.442

Proctor, H. C., \& Harder, L. D. (1995). Effect of pollination success on floral longevity in the orchid Calypso bulbosa (Orchidaceae). American Journal of Botany, 82(9), 1131-1136. https://doi.org/10.2307/2446066

Rafferty, N. E., \& Ives, A. R. (2010). Effects of experimental shifts in flowering phenology on plant-pollinator interactions. Ecology Letters, 14(1), 69-74. https://doi.org/10.1111/j.14610248.2010.01557.x

Schaal, B. A., \& Leverich, W. J. (1980). Pollination and banner markings in Lupinus texensis (Leguminosae). The Southwestern Naturalist, 25(2), 280-282. https://doi.org/10.2307/3671260

Schoen, D. J., \& Ashman, T. (1994). The evolution of floral longevity: resource allocation to maintenance versus construction of repeated parts in modular organisms. Evolution, 49(1), 131-139. https://doi.org/10.1111/j.1558-5646.1995.tb05965.x

Sharam, G. J., \& Turkington, R. (2005). Diurnal cycle of sparteine production in Lupinus arcticus. Canadian Journal of Botany, 83(10), 1345-1348. https://doi.org/10.1139/b05-104

Stead, A. D. (1992). Pollination-induced flower senescence: a review. Plant Growth Regulation, 11, 13-20. https://doi.org/10.1007/BF00024427

Stead, A. D., \& Reid, M. S. (1990). The effect of pollination and ethylene on the colour change of the banner spot of Lupinus albifrons (Bentham) flowers. Annals of Botany, 66 (6), 655-663. https://doi.org/10.1093/oxfordjournals.aob.a088080 
Straka, J. R., \& Starzomski, B. M. (2014). Humming along or buzzing off? The elusive consequences of plant-pollinator mismatches. Journal of Pollination Ecology, 13(14), 129-145. https://doi.org/10.26786/1920-7603(2014)18

Straka, J. R.,\& Starzomski, B. M. (2015). Fruitful factors: What limits seed production of flowering plants in the alpine? Oecologia, 178, 249-260. https://doi.org/10.1007/s00442-014-3169-2

van Doorn, W. G. (1997). Effects of pollination on floral attraction and longevity. Journal of Experimental Botany, 48(314), 1615-1622. https://doi.org/10.1093/jxb/48.9.1615

Wainwright, C. (1978). The floral biology and pollination ecology of two desert lupines. Bulletin of the Torrey Botanical Club, 105(1), 24-38. https://doi.org/10.2307/2484260

Weiss, M. R., \& Lamont, B. B. (1997). Floral color change and insect pollination: A dynamic relationship. Isreal Journal of Plant Sciences, 45, 185-199. https://doi.org/10.1080/07929978.1997.10 676683

Willow, J., Tamayo, M., \& Jóhannsson, M. H. (2017). Potential impact of Nootka lupine (Lupinus nootkatensis) invasion on pollinator communities in Iceland. Journal of Icelandic Agricultural Sciences, 30, 51-54. https://doi.org/10.16886/IAS.2017.06 